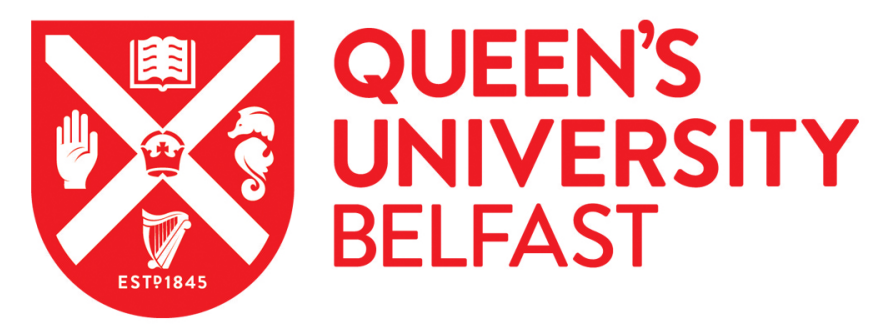

\title{
Patient and family involvement in escalating concerns about clinical deterioration in acute adult wards: A qualitative systematic review
}

McKinney, A., Fitzsimons, D., Blackwood, B., \& McGaughey, J. (2020). Patient and family involvement in escalating concerns about clinical deterioration in acute adult wards: A qualitative systematic review. Nursing in Critical Care. https://doi.org/10.1111/nicc.12582

Published in:

Nursing in Critical Care

Document Version:

Peer reviewed version

Queen's University Belfast - Research Portal:

Link to publication record in Queen's University Belfast Research Portal

Publisher rights

(c) 2020 British Association of Critical Care Nurses

This work is made available online in accordance with the publisher's policies. Please refer to any applicable terms of use of the publisher.

\section{General rights}

Copyright for the publications made accessible via the Queen's University Belfast Research Portal is retained by the author(s) and / or other copyright owners and it is a condition of accessing these publications that users recognise and abide by the legal requirements associated with these rights.

Take down policy

The Research Portal is Queen's institutional repository that provides access to Queen's research output. Every effort has been made to ensure that content in the Research Portal does not infringe any person's rights, or applicable UK laws. If you discover content in the Research Portal that you believe breaches copyright or violates any law, please contact openaccess@qub.ac.uk. 
Patient and family involvement in escalating concerns about clinical deterioration in acute adult wards: a qualitative systematic review

Aidín McKinney ${ }^{a^{*}}$, Professor Donna Fitzsimons ${ }^{a}$, Professor Bronagh Blackwood ${ }^{b}$ and Dr Jennifer McGaughey ${ }^{a}$

* Corresponding author: amckinney04@qub.ac.uk a School of Nursing and Midwifery, Queen's University Belfast, 97 Lisburn Road, Belfast BT9 7BL, Northern Ireland Tel: 02890972233

Author details and institutional affiliations:

Aidín McKinneya, MSc, BSc(Hons), RGN https://orcid.org/0000-0002-65895904 Lecturer/ PhD Candidate (amckinney04@qub.ac.uk)

Donna Fitzsimons a , PhD, RGN https://orcid.org/0000-0002-8299-682X Professor/Head of School of Nursing and Midwifery (d.fitzsimons@qub.ac.uk),

Bronagh Blackwood ${ }^{\mathrm{b}}$, PhD, MSc, RGN https://orcid.org/0000-0002-4583-5381 Professor (b.blackwood@qub.ac.uk)

Jennifer McGaugheya, PhD, MSc, RGN https://orcid.org/0000-0003-2295-1117 Reader (j.mcgaughey@qub.ac.uk)

a. School of Nursing and Midwifery, Queen's University Belfast, 97 Lisburn Road, Belfast BT9 7BL, Northern Ireland.

b. Wellcome-Wolfson Institute for Experimental Medicine, School of Medicine, Dentistry and Biomedical Sciences, Queen's University Belfast, 97 Lisburn Rd, Belfast BT9 7BL, Northern Ireland

Conflict of interest: No conflict of interest has been declared by the authors.

Ethical Approval: Not required.

Funding: This work was conducted as part of a Doctoral Research Fellowship funded by the Health Service Improvement Programme, Health Service Executive in Ireland. 
Background: Despite international standards for recognition and response to deterioration, warning signs are not always identified by staff on acute hospital wards. Patient and family-initiated escalation of care schemes have shown some benefit in assisting early recognition, but are not widely used in many clinical practice areas.

Objectives: To explore (a) patients' and relatives' experiences of acute deterioration and (b) patients', relatives' and healthcare professionals' perceptions of the barriers or facilitators to patient and family-initiated escalation of care in acute adult hospital wards.

Methods: We conducted a qualitative review using Cochrane methodology. Two reviewers independently screened studies, extracted data and appraised the quality using a qualitative critical appraisal tool. Findings were analysed using thematic synthesis and confidence in findings was assessed using GRADECERQual.

Search Strategy: MEDLINE, CINAHL, EMBASE, PsychINFO databases and grey literature from 2005 to August 2019.

Inclusion Criteria: Any research design that had a qualitative element and focused on adult patients' and relatives' experiences of deterioration and perceptions of escalating care.

Results: We included five studies representing 120 participants and assessed the certainty of evidence as moderate using GRADE-CERQual. Findings indicated that a number of patients/relatives have the ability to detect acute deterioration, however various factors act as both barriers and facilitators to being heard. These include personal factors, perceptions of role, quality of relationships with healthcare staff and organisational factors. Theoretical understanding suggests that patient and relative involvement in escalation is dependent on both inherent capabilities and the factors that influence empowerment.

Conclusion: This review highlights that patient and family escalation of care interventions need to be designed with the aim of improving patient/relative clinician collaboration and the sharing of responsibility.

Relevance to practice: These factors need to be addressed to promote more active partnerships when designing and implementing patient and family-initiated escalation of care interventions.

\section{Systematic review registration: PROSPERO ${ }^{32}$}

Keywords: Clinical deterioration, family, hospitals, patients, nurses/nursing, perception, Rapid Response Team, early warning, family activation, patient and family escalation of care, patient advocate. 


\section{INTRODUCTION}

Failure to detect and respond to clinical deterioration early enough remains challenging, despite the implementation of Rapid Response Systems (RRS) on acute hospital wards. ${ }^{1,2}$ Evaluation of RRS highlights the complex interplay of organisational, behavioural and personal factors limiting the certainty of evidence regarding their effectiveness. ${ }^{3,4}$ To address this problem, the contribution that patients and/or families can make to the detection and response to acute deterioration is advocated as an additional safety mechanism. ${ }^{2,5-7}$

\section{BACKGROUND}

Early recognition of clinical deterioration aims to facilitate timely intervention and reduce morbidity associated with acute deterioration. ${ }^{8,9}$ Enhancing the processes for doing this are expected to yield patient benefit. ${ }^{2,6}$ The patient and often their family provide useful context to the patients 'usual health state', which is helpful as a baseline, should the patient subsequently become acutely unwell. In keeping with this, families are increasingly being recognised as having a role to play in detecting and responding to patient deterioration. ${ }^{5,6}$ This has led to a number of patient and family-initiated escalation of care schemes being implemented internationally, particularly in the United States of America (USA), Australia and to a lesser extent, the United Kingdom (UK). ${ }^{6,10-12}$ The purpose of these schemes is to legitimise and value patients and/or relatives concerns regarding clinical deterioration by providing access to resources and healthcare professionals who can deal with any worries or problems. ${ }^{13,14}$

Evaluations to understand the effectiveness of these schemes ${ }^{15,16}$ have indicated that on occasions relatives identified deterioration and escalated a number of patients that were undetected by healthcare staff. $10,11,17-19$ Studies also identified that they are valued by patients and relatives $11,16,17,20$ and are associated with increased feelings of reassurance and patient empowerment. ${ }^{11,} 13$ However, systematic reviews ${ }^{21,22}$ highlight the overall limited evidence to determine the impact of such schemes and indicate that many have been introduced into practice without adequate evidence to support their true value. ${ }^{21,23}$ However, given the positive signals to date, it is worthwhile carrying out further research in this area, 
prior to introducing and implementing these schemes more widely. As with any complex intervention, implementing these schemes in practice may not be quite so straight forward. In particular, there is a need to further investigate and explore the assumptions underpinning these schemes, such as: can patients and relatives recognise signs of deterioration; is it a role they wish to adopt and what are the barriers and facilitators to them escalating concerns. ${ }^{23} \mathrm{~A}$ recent study from the paediatric setting indicated that parents feel that they can recognise deterioration in their child and outlined a number of barriers and facilitators that may impact on parent involvement in escalation of care. ${ }^{24} \mathrm{~A}$ key facilitator was the belief that parents would have no hesitation in taking on this role. ${ }^{24}$ One possible reason for this is that family-centred care is a widely accepted ethos in paediatric areas. ${ }^{25}$ The role of families/ parents is different in paediatrics in that they are viewed as a child's guardian and hence there is a fundamental acceptance that parents have an inherent responsibility to advocate for their children and to ensure their safety. ${ }^{26}$ In adults, however, the patient is perceived to be autonomous and not necessarily in need of guardianship or advocacy. Consequently, the findings of Gill et al's ${ }^{24}$ study may not necessarily be transferable to the adult setting. However, when adult patients become acutely unwell they are at risk of being unable to succinctly articulate when something is wrong. In addition, paediatric settings facilitate unrestricted visiting while visiting of adults in hospital is still limited to short time frames in many clinical areas. ${ }^{27}$ As a result, there is less opportunity for family to advocate on behalf of the patient. Nonetheless this does not mean that this is not a laudable endeavour.

It is therefore essential to explore these issues further, particularly within the adult setting as they may provide valuable insights that could inform the development and determine the future success of similar interventions. To our knowledge, there is no qualitative systematic review that has explored these factors. Such a review could help to explain the perspectives of various stakeholders and generate greater insights into why these interventions may succeed or fail. This information can be used to influence the design and implementation of future patient and relative-initiated schemes in the adult setting. 


\section{THE REVIEW}

\section{Aim}

The aim was to explore (a) patients' and relatives' experiences of acute deterioration and (b) patients', relatives' and healthcare professionals' perceptions of the barriers or facilitators to patient and family-initiated escalation of care in acute adult hospital wards.

\section{Design}

We conducted a systematic literature search using Cochrane methodology, previously outlined in a published systematic review protocol ${ }^{28}$ as part of a larger, funded research study. ${ }^{29}$ Qualitative thematic synthesis outlined by Thomas and Harden ${ }^{30}$ was utilised to analyse data as it is a method specifically designed to synthesise qualitative data. ${ }^{31}$ To enhance quality and transparency we registered the review protocol prospectively with PROSPERO ${ }^{32}$ and followed the Enhancing transparency in reporting the synthesis of qualitative research (ENTREQ) guidelines. ${ }^{31}$

\section{Search strategy}

We searched CINAHL, MEDLINE, EMBASE and PsycINFO databases from 2005 (when patient-family escalation care schemes were introduced) until August 2019 and conducted a grey literature search of OpenGrey, ${ }^{33}$ Google Scholar and reference lists of included studies. The search strategy was developed with assistance from a subject librarian (Appendix 1) and translated into each database using appropriate controlled vocabulary. A scoping search identified the free text and MESH terms related to clinical deterioration, hospital rapid response team, experiences, attitude, patients, family and health personnel. 


\section{Inclusion/exclusion criteria}

We included any type of research design that had a qualitative element. Studies that focused on adult patients, relatives and healthcare professionals in acute hospital settings were included. We excluded: studies from paediatric, maternity, mental health, non-acute wards, specialist areas (accident and emergency, intensive care unit, high-dependency unit) and community (non-hospital) settings, as the process for recognition and referral is different than that of patients on acute wards in hospital where EWS and RRS are utilised; ${ }^{34}$ healthcare professionals' experiences or views of deterioration; and patients', relatives' and healthcare professionals' views of rapid response systems not initiated by patients or relatives. There was no language restriction.

One author (AMcK) conducted the searches, exported the search results to Mendeley and screened titles and abstracts for full text review. Two authors (AMcK, JMcG) independently considered potentially relevant studies for inclusion based on study eligibility criteria and any disagreements were resolved by consensus.

\section{Search outcome}

We screened the title and abstract of 2113 studies and excluded irrelevant titles and abstracts. Full text of 23 potentially relevant articles were assessed and we excluded a further 18 studies (Appendix 2).

Five qualitative studies were included in the review, consisting of the experiences of 88 patients and 32 relatives reported in four studies. ${ }^{35-38}$ One study ${ }^{39}$ reported on the experiences and views of patients, relatives and healthcare staff however did not clearly report on the sample size from each group $(n=56)$.

\section{Quality appraisal}

Quality appraisal was conducted independently by (AMcK, JMcG) using an adaptation of the Critical Appraisal Skills Programme ${ }^{40}$ tool and the Popay framework ${ }^{41}$ as previously used by Jordan et al. ${ }^{42}$ Overall assessment of quality 
for each study was rated as high (criteria appropriately applied), moderate (criteria not reported) or low (criteria inappropriately or not applied) and any disagreements were settled by consensus.

\section{Data abstraction}

Two authors (AMcK, JMcG) extracted study data independently using a modified version of the Effective Practice and Organisation of Care (EPOC) data extraction form ${ }^{43}$ and the Template for Intervention Description and Replication (TIDieR) checklist. ${ }^{44}$ Modification of the EPOC data extraction form involved selecting only criteria relevant to our review regarding the phenomena of interest, population, study setting, design, methods and study findings. The TIDieR checklist was used as recommended by Hoffman et $\mathrm{a}^{45}$ and the Cochrane Collaboration ${ }^{46}$ to improve the completeness of intervention descriptions within systematic reviews.

\section{Data analysis/synthesis}

Two authors (AMcK, JMcG) independently conducted thematic synthesis in three rigorous stages as outlined by Thomas and Harden. ${ }^{30}$ Stage one involved continually applying line by line coding to small sections within the text and employing the constant comparison method to compare codes between studies. ${ }^{47}$ Stage two involved grouping these codes into related areas which shared common meaning to construct "descriptive" themes. These descriptive themes were underpinned by phrases and words commonly used to explain experiences of deterioration and the process of escalating care on acute hospital wards. The third stage involved iteratively examining, comparing and analysing the descriptive themes across studies to generate a stage of interpretation that helped to "go beyond" the content of the original studies. ${ }^{30}$ This enabled the creation of new analytical themes which facilitated deeper understanding of the data. ${ }^{30}$ Discussion and agreement between authors facilitated the final development of analytical themes. ${ }^{30}$

We used GRADE-CERQual (Grading of Recommendations, Assessment, Development and Evaluation Confidence in the Evidence from Reviews of 
Qualitative research $)^{48}$ to assess the confidence in the qualitative synthesis findings (Appendix 3). To determine how much certainty can be placed in each review finding (high/moderate/low/very low), four components contributed to the assessment; methodological limitations, relevance, coherence and adequacy of data. $^{48}$

\section{RESULTS}

\section{Study characteristics}

Study design included: two qualitative, exploratory design studies; 35,36 one qualitative cross-sectional design study; ${ }^{37}$ one interpretive qualitative research design study; ${ }^{38}$ and one retrospective chart review with qualitative data. ${ }^{39}$ One study was conducted in the UK, ${ }^{35}$ three in Australia ${ }^{36,38,39}$ and one in New Zealand. ${ }^{37}$ Study characteristics are summarised in Table 1.

Participants (patients, relatives, healthcare professionals) were mainly recruited from acute adult medical or surgical wards in large metropolitan or regional hospitals in high-income countries. ${ }^{35-37}$ One study recruited from communitybased consumer organisations, ${ }^{38}$ who had experiences of being patients or family members of past patients in acute hospitals. Age of participants ranged from 2786 years in four studies, ${ }^{35-38}$ the reporting of age from one study was restricted as patients age was grouped by gender. ${ }^{39}$

One study had a patient and family-initiated escalation of care intervention in place. ${ }^{39}$ Remaining studies had EWS and RRS without a family escalation of care scheme. Reporting of the intervention as per the TIDieR checklist ${ }^{44}$ was limited, with only the name of the intervention, goal and a limited overview of the procedures and activities outlined. ${ }^{39}$ 


\section{Quality appraisal and confidence in findings}

All included studies were assessed as moderate ${ }^{39}$ or high quality. ${ }^{35-38}$ Overall studies utilised a relatively straightforward and functional approach to the study design which had a logical fit with the studies aims (Table 2). Overall confidence in evidence was rated as moderate using GRADE-CERQual approach (Table 3).

\section{Synthesis Findings}

The three stages of thematic analysis resulted in the generation of two analytical themes: [1] Inherent capabilities and [2] Empowerment Influencers. These analytical themes provide overall meaning and a greater theoretical understanding of the initial descriptive themes following further synthesis and interpretation. These analytical themes emphasise the key factors that influence patients'/ relatives' ability to recognise deterioration and escalate care. One study ${ }^{39}$ provided limited evidence of healthcare professionals' experiences.

\section{Inherent Capabilities}

The ability to recognise deterioration is dependent on factors that are individual to the person. Identifying changes in condition or appreciating their significance appears to emanate from an inherent knowing of self and/or significant others. The findings from the reported studies clearly indicated that in many cases patient and/or relative participants instinctively reported an awareness that something was not right. Buetow and Mintoft ${ }^{49}$ acknowledge that this instinctive knowing is related to intuition and identifies that this involves implicit processes that may not even be consciously recognised by the individual. It would therefore seem this "tacit knowing without conscious reasoning" 49 (p434) is inherent in each individual in varying degrees and greatly influences their ability to seek help. This theme incorporates descriptive sub-themes of knowing self / significant other and appreciating significance of symptoms. 


\section{Knowing self/significant other}

Experiences of deterioration were reported as being extremely individual. Variation existed in relation to patients' and relatives' awareness of deterioration, ranging from total awareness of acute changes to a complete inability to recognise changes in their condition ${ }^{35-38}$ (4 studies; moderate confidence). Studies reported that some patients recounted they knew their own bodies better than anyone. ${ }^{35-38}$ These studies also inferred that on occasions patients and/or relatives felt that their awareness of changes occurred prior to the healthcare professional being aware. ${ }^{36,37}$ In contrast, Rainey et $\mathrm{al}^{35}$ reported that in a significant number of cases both patients and relatives were unaware of deterioration.

\section{Appreciating significance of symptoms}

The ability to appreciate the significance of the deterioration was a common theme in all five studies (5 studies; moderate confidence). Although three studies highlighted that patients were aware of deterioration, ${ }^{36,37,38}$ it did not always follow that patients appreciated the significance of the changes. ${ }^{35,} 36$ The inability to appreciate the severity of illness was often reported as being a consequence of their underlying condition or the extent of their deterioration. ${ }^{35,37}$ In two studies the onus appeared to rest more with the family to appreciate the severity of the situation. ${ }^{35,37}$ However, some patients very much appreciated the severity of their condition, to such an extent that it provoked feelings of extreme anxiety. ${ }^{37}$ Only one reported on healthcare professionals' views. ${ }^{39}$ This study indicated that in some cases where patients/relatives reported a concern, the clinician considered it to be a "complaint" 39 highlighting that there appeared to be a mismatch at times between clinician and patient/relative perceptions.

\section{Empowerment Influencers}

Further analysis of the key barriers and facilitators to being involved in escalating care indicate that patients/relatives appear to be affected by the factors that influence empowerment. Four components have been identified in the literature as being fundamental to the process of patient empowerment: understanding of the 
patient/healthcare professional role, acquisition by patients/relatives of sufficient knowledge to enable engagement with the healthcare professional, patient/relative skills and finally the presence of a facilitating environment. ${ }^{50}$ These factors were apparent to a greater or lesser extent in each of the included studies. Collectively, this contributed to the realisation that the extent to which these empowerment factors were enabled or not influences the ability to become involved in recognising deterioration and in escalating care. Numerous complexities may make it more challenging to influence a number of these empowerment factors, such as organisational culture. However, encouraging factors such as positive relationships and communication can promote empowerment, enabling escalation of care to become less difficult. This theme incorporates five descriptive subthemes: personal characteristics, perceptions of roles, communication skills, developed relationships and organisational/ logistical factors.

\section{Personal characteristics}

All five studies reported that the onset of physical changes prompted some patients and/or relatives to speak to a doctor or nurse (5 studies; moderate confidence). However, not all patients and relatives were aware of a change and this acted as a barrier to them seeking help. ${ }^{35,37}$

Patients and relatives who had previous experience or knowledge relating to illness appeared more likely to seek help. ${ }^{35,36,38}$ In contrast, those who had little previous knowledge were less confident in their ability to escalate care. ${ }^{36}$ However, this is not necessarily always the case as some patients and relatives with limited previous experiences of acute illness were able to identify symptoms. ${ }^{35}$

Four studies reported that individual personality traits determined how patients and/or relatives responded to changes and raised concerns. ${ }^{35-38}$ Those patients/relatives who were confident were reported as being more likely to raise concerns than quieter personality types. ${ }^{36,} 38$ Additionally, those who had a more stoic personality were more likely to persevere with changes. ${ }^{36,37}$

Personal beliefs and the value attached to patient/ family involvement in escalating care also impacted on patients'/relatives' wishes to be involved. ${ }^{36-38}$ Many voiced 
support for a family-initiated escalation of care service, indicating it would provide reassurance and an avenue to voice concerns; 37,39 and may act as a solution to delays in accessing care. ${ }^{36}$ This positive perception may encourage patients/relatives to be more willing to engage with such schemes.

\section{Perceptions of roles}

A common finding across all studies was how perceptions of the patient/relative/healthcare professional role influenced their thinking and contributed to their ability to speak up (5 studies; moderate confidence). Four studies consistently reported that patients and relatives felt that healthcare professionals had superior knowledge and it was not the patients'/relatives' role to question their care. ${ }^{35-38}$ There appeared to be an overarching sense of having complete confidence that staff would identify a change in condition and know what to do, ${ }^{35,37,38}$ so much so, that some patients/relatives appeared to be willing to take a passive role in hospital. ${ }^{36}$ These factors were barriers to patients/relatives escalating their concerns. A power imbalance was perceived to exist between patients and healthcare professionals in hospitals. ${ }^{35}, 36$ This notion that the "healthcare professional knows best" may also be portrayed to a certain extent by healthcare professionals themselves. For example, on some occasions where patients/family members had reported deterioration they perceived their concerns were not taken seriously by health professionals. ${ }^{35,39}$

\section{Communication skills}

Communication issues were reported across all studies indicating that many patients and relatives described how they had reported concerns about care but felt that they had not been listened to (5 studies; moderate confidence). This perceived lack of being heard led to feelings of fear, frustration, ${ }^{38}$ increased vulnerability, ${ }^{36}$ increased feelings of concern ${ }^{37}$ and mistrust in healthcare staff. ${ }^{35}$, 38, 39 However, patients and relatives also reported occasions when they felt that staff did listen ${ }^{35-37}$ and expressed how this contributed towards feeling reassured, ${ }^{35}$ safe and relieved. ${ }^{37}$ 


\section{Developed relationships}

The quality of relationships built between patients and staff have an impact on patients/relatives' ability to escalate care ( 5 studies; moderate confidence). Those participants who felt that they had developed closer relationships with staff felt more at ease with approaching healthcare professionals and this facilitated raising concerns. ${ }^{35,36}$ On the other hand, some patients and relatives reported that despite having an excellent relationship with their doctor or nurse they would be reluctant to raise concerns in case they were perceived as being a burden, ${ }^{36-38 ~ " d i f f i c u l t " ~}{ }^{35}$, ${ }^{33}$ or imposing on already busy staff. ${ }^{37}$ In addition, uncertainty regarding how to engage with staff and knowing who to go to added to the problem. ${ }^{35,38,39}$

\section{Organisational/Logistical Factors}

Patients' and relative's willingness/ unwillingness to escalate care also related to perceptions that the organisational systems were not designed or resourced to expedite access to services, even during times of concern ${ }^{35-38}$ (4 studies; moderate confidence). Patients and relatives reported that staff seemed overburdened, too busy to talk and they did not want to impose on already stretched resources. ${ }^{35-37}$

\section{DISCUSSION}

Patients' and relatives' experiences of deterioration and their ability to recognise changes in their condition and/ or actively engage in escalating care is very much influenced by their inherent capabilities of 'knowing' and personal characteristics, perception of roles, communication skills, developed relationships and organisational/logistical factors. These findings are similar to other studies which suggest that a complex interplay of personal, professional and contextual factors will impact on patient and family involvement in escalation of care. ${ }^{51,52}$ The review found limited evidence on the perceptions of healthcare staff regarding the factors enabling or constraining patient/family participation. 
Although patients and relatives in this review varied as to the extent to which they could detect deterioration, it is apparent that in many instances they were able to do so. This resonates with the view that has begun to emerge more in recent years, in that the patient is an expert on their own bodies and has an inherent knowledge of what is right or wrong for them. ${ }^{53}$ Similar to our findings, the value of intuition has been identified as being important in recognising deterioration in the literature particularly amongst nurses. ${ }^{54-56}$ However, patient intuition may not always be viewed as credible by healthcare professionals. ${ }^{49}$ Factors influencing patient empowerment are considered to be central to enabling or hindering patient and family involvement in care activities. This includes personal factors which influence whether or not patients/relatives will engage in escalating care. This is similar to a systematic review by Vaismoradi et $\mathrm{al}^{57}$ which found that patients' health conditions, knowledge and previous experiences and beliefs all influence their engagement with patient-safety initiatives. However, our findings also highlight that this is not necessarily exclusively the case and that patients/relatives with previous experience of illness and awareness of symptoms did not always engage in calling for help. This suggests that other factors may serve as a more dominant influence.

Consistent with the literature, a key influencing factor impacting on the ability of patients and relatives to escalate care were perceptions of the patient/healthcare professional role. ${ }^{50,58}$ Some patients/relatives felt that healthcare professionals 'knew best', ${ }^{59}$ resulting in the adoption of a passive role in hospital. This suggests that patients/relatives may be reluctant to overstep what might be considered to be the traditional patient/provider role ${ }^{57}$ and fear voicing their concerns, even when they consider something is seriously wrong. ${ }^{60,61}$ This contrasts with study findings in the paediatric setting which indicated that relatives would feel confident to take on the role to escalate care, even if this had consequences such as upsetting staff. ${ }^{24}$ This indicates that relatives' perspectives in caring for adults may differ.

The patient-provider relationship impacted on patient/relative empowerment and similar to other studies suggested that the presence of a facilitating environment promoted participation in care. ${ }^{50}$ Findings suggested that when patients/relatives had built close relationships with healthcare professionals, this served as a facilitator towards raising concerns. This indicates that clinicians have a significant 
influence on patients/relatives' ability to participate in safety related behaviours. ${ }^{62}$, 63, 64 However, in keeping with other studies, patients/relatives reported being worried about escalating care in case it affected relationships with healthcare professionals. ${ }^{60,61,65}$ The fear of being rebuffed, chastised or offending healthcare staff was a significant barrier to speaking up, even in the event of serious failings. In particular there appears to be a reluctance to engage in safety behaviour that may be viewed as somewhat confrontational or digresses from the traditional patient role by questioning clinicans. ${ }^{62,63,66}$ Other studies support this view and indicate that it may stem from a fear of being perceived as difficult ${ }^{67}$ or of causing a negative response from clinicians. ${ }^{68}$ This supports the need for increased collaboration between patients and clinicians on safety issues ${ }^{66}$ and to more actively consider how to enhance communication channels in the clinician patient/relative relationship. ${ }^{58,63,64,69}$

A busy organisational setting and a perceived lack of resources were reported as a strong barrier in preventing patients/relatives to speak up about concerns. This concurs with other findings that when clinicians' time is perceived as being constrained due to work pressure, patients are reluctant to engage with them. ${ }^{62,65}$, 70 This reinforces the need to address organisational issues and create an environment in which the patient or relative feel it is permissible to seek help, even when staff are perceived as being busy. ${ }^{71}$

\section{Strengths and Limitations}

The strengths of our review were the comprehensive search strategy developed with librarians, the robust methods used to screen, extract and analyse data independently by two reviewers and the findings support and contribute to the overall body of knowledge in this area.

We acknowledge that the small number of qualitative studies which were all conducted in high income countries, mainly in Australia and New Zealand, limits the generalisability of the findings. These countries have different healthcare systems which may not be reflective of those in other countries. The limited number of studies also reflects the dearth of qualitative studies that explore experiences of deterioration and/or patient/family involvement in escalation of 
care. This reinforces the need for further, more robust studies to be carried out in this area.

\section{Implications and recommendations for practice}

The moderate level of confidence (GRADE-CERQual) in our findings highlights the need for family escalation of care interventions to be designed with the aim of improving patient/relative - clinician collaboration and the sharing of responsibility. This underscores the need to both address hierarchical power imbalances and patient passivity in order to help patients and relatives to move more confidently towards feeling that they have "permission to participate". ${ }^{72}$ The role of patient / relative intuition and how it may be used to complement clinician judgement should be considered. ${ }^{49}$ These proposed changes also require consideration of the organisational context and the policies and resources that either promote or hinder partnering with patients/relatives. ${ }^{47}$

\section{CONCLUSION}

This systematic review highlights that patients' and relatives' ability to recognise deterioration and become involved in escalating concerns about acute deterioration varies and is influenced by personal factors that are inherent to the individual as well as factors that impact on empowerment. These various factors can make it challenging for patients and families to articulate concerns about a change in condition. There is a need to improve patient and family engagement in this area and to consider the processes and interventions required to enhance their ability to have a greater voice in raising concerns about deterioration. This requires changes to ward culture and to the factors that influence empowerment such as role perceptions, knowledge, skills and power dynamics. Future research into the credibility of patient/relative intuition and the development and feasibility testing of interventions which addresses power imbalances and organisational context is also required. 


\section{What is already known?}

- Timely detection of and response to acute deterioration continues to be problematic.

- Evidence evaluating patient or family escalation of concerns about acute deterioration focuses on quality improvement versus research and paediatric versus adult setting with limited patient or public involvement in their design.

\section{What this paper contributes}

- This is the first review of qualitative research reporting experiences of deterioration and perceptions of patient and family involvement in escalating care from the perspective of the patient, family and staff from acute adult ward settings.

- Involving patients and their families as partners in escalating concerns about clinical deterioration may improve patient outcomes, but their ability to do so is impacted by ward culture and the factors that influence empowerment.

- Interventions to improve patient/family empowerment in escalating concerns about clinical deterioration may contribute to earlier assessment and management allowing patients to be stabilised on the ward or transferred to critical care in a more timely way. 


\section{References}

1. Donaldson LJ, Panesar SS, Darzi A. Patient-safety-related hospital deaths in England: thematic analysis of incidents reported to a national database, 20102012. PLoS Med 2014;24:11(6):e1001667. https://doi:10.1371/journal.pmed.1001667 9.

2. Australian Commission on Safety and Quality in Healthcare. National Safety and Quality Health Service Standards/ Safety and Quality. 2018 https://www.safetyandquality.gov.au/standards/nsqhs-standards [Accessed 13 Sep. 2019].

3. McGaughey J, O'Halloran P, Porter S, Trinder J, Blackwood B. Early warning systems and rapid response to the deteriorating patient in hospital: a realist evaluation. $J$ Adv Nurs 2017;12: 3132. https://doi.org/10.1111/jan.13367.

4. McGaughey J, Alderdice F, Fowler R, et al. Outreach and Early Warning Systems (EWS) for the prevention of Intensive Care admission and death of critically ill adult patients on general hospital wards. Cochrane Database of Syst Rev 2007; 3. https://doi: 10.1002/14651858.CD005529.pub2.

5. World Health Organisation. Exploring patient participation in reducing healthcare related safety risks.2013.

http://www.euro.who.int/en/publications/abstracts/exploring-patientparticipation-in-reducing-health-care-related-safety-risks [Accessed 8th September 2019].

6. Institute for Healthcare Improvement. Rapid response teams: reducing codes and raising morale.100kLivesCampaign. 2006.

http://www.ihi.org/resources/Pages/ImprovementStories/DeliveringGreatCare EngagingPatientsandFamiliesasPartners.aspx [Accessed 18 Oct 2019].

7. Centre for Clinical Practice at NICE (UK). Acutely ill patients in hospital: recognition of and response to acute illness in adults in hospital. 2007 http://www.ncbi.nlm.nih.gov/pubmed/21204323 [Accessed13 Sept 2019].

8. Beitler JR, Link N, Bails DB, Hurdle K, Chong DH. Reduction in hospital-wide mortality after implementation of a rapid response team: a long-term cohort study. Crit Care 2011;15:R269. https://doi.org/10.1186/cc10547. 
9. Chen J, Ou L, Hillman K, et al (2014). The impact of implementing a rapid response system: a comparison of cardiopulmonary arrests and mortality among four teaching hospitals in Australia. Resuscitation, 2014;85:1275-1281. https://doi.org/10.1016/j.resuscitation.2014.06.003.

10. Brady PW, Zix J, Brilli R, et al. Developing and evaluating the success of a family activated medical emergency team: a quality improvement report. BMJ Qual Saf 2015;24:203-11. https://doi: 10.1136/bmjqs2014-003001.

11. Odell M, Gerber K, Gager M. Call 4 Concern: patient and relative activated critical care outreach. $\mathrm{Br} J$ Nurs 2010;19:1390-5. https://doi. org/10.12968/bjon.2010.19.22.1390.

12. Vorwerk J, King L. Consumer participation in early detection of the deteriorating patient and call activation to rapid response systems: a literature review. J Clin Nurs 2016;25:38-52. https://doi: 10.1111/jocn.12977.

13. Greenhouse PK, Kuzminsky B, Martin SC, Merryman T. Emergency: Calling a Condition $\mathrm{H}(\mathrm{elp})$-Patients and families often know better than clinicians when a patient is failing. Allowing them to summon a rapid response team can save lives. Am J Nurs 2006;106:63-6. https://doi.org/10.1097/00000446200611000-00021.

14. Lawton R, Armitage $\mathrm{G}$. The role of the patient in clinical safety. Health Foundation; 2012http://www.health.org.uk/sites/default/files/TheRoleOfThePatientInClinica ISafety.pdf. [Accessed 18 Oct 2019].

15. Hueckel RM, Mericle JM, Frush K, Martin PL, Champagne MT. Implementation of condition help: family teaching and evaluation of family understanding. $J$ Nurs Care Qual 2012;27:176-81. https://doi: 10.1097/NCQ.0b013e318235bdec.

16. Gerdik C, Vallish RO, Miles K, et al. Successful implementation of a family and patient activated rapid response team in an adult level 1 trauma center. Resuscitation 2010;81:1676-1.https://doi:10.1016/j.resuscitation.2010.06.020.

17. Odell M. Patient-and relative-activated critical care outreach: a 7-year service review. Br J Nurs 2019;28:116-21.

18. Bavare AC, Thomas JK, Elliott EP, Morgan AC, Graf JM. Family-initiated pediatric rapid response: characteristics, impetus, and outcomes. J Healthc Qual 2018;40:103-9. http://dx.doi.org/10.1097/JHQ.0000000000000096. 
19. Ray EM, Smith R, Massie S, et al. Family alert: implementing direct family activation of a pediatric rapid response team. Jt Comm J Qual Patient Saf 2009;35:AP1-6.

20. Bogert S, Ferrell C, Rutledge DN. Experience with family activation of rapid response teams. Medsurg Nurs 2010;19: 215-222.

21. Albutt AK, O'Hara JK, Conner MT, Fletcher SJ, Lawton RJ. Is there a role for patients and their relatives in escalating clinical deterioration in hospital? A systematic review. Health Expect 2017;20:818-25. https://doi: 10.1111/hex.12496.

22. Gill FJ, Leslie GD, Marshall AP. The impact of implementation of family initiated escalation of care for the deteriorating patient in hospital: a systematic review. Worldviews Evid Based Nurs 2016;13:303-13. https://doi.org/10.1111/wvn.12168.

23. Gill FJ, Leslie GD, Marshall AP. Family initiated escalation of care for the deteriorating patient in hospital: family centred care or just "box ticking". Aust Crit Care 2016;29:195-200. https://doi.org/10.1016/j.aucc.2016.07.004.

24. Gill FJ, Leslie GD, Marshall AP. Barriers and facilitators to implementing a process to enable parent escalation of care for the deteriorating child in hospital. Health Expect 2018;21:1095-103. https://doi: 10.1111/hex.12806.

25. Foster MJ, Whitehead L, Maybee, P. Cullens V. The parents', hospitalized child's, and health care providers' perceptions and experiences of family centered care within a pediatric critical care setting: A metasynthesis of qualitative research. J. Fam. Nurs 2013;19: 431-468. https://doi: 10.1177/1074840715618193.

26. Heath G, Montgomery H, Eyre C, et al. Developing a tool to support communication of parental concerns when a child is in hospital. Healthcare 2016;4:9. Multidisciplinary Digital Publishing Institute. doi:10.3390/healthcare4010009.

27. Hurst H, Griffiths J, Hunt C, Martinez E. A realist evaluation of the implementation of open visiting in an acute care setting for older people. BMC Health Serv Res 2019;19:867 https://doi.org/10.1186/s12913-019-4653-5.

28. McKinney A, Fitzsimons D, Blackwood B, McGaughey J. Patient and familyinitiated escalation of care: a qualitative systematic review protocol. Syst Rev 2019; 8:1-8. https://doi.org/10.1186/s13643-019-1010-z. 
29. McKinney A, Fitzsimons D, Blackwood B, White M, McGaughey J. Co-design of a patient and family-initiated escalation of care intervention to detect and refer patient deterioration: Research protocol. J Adv Nurs 2020; 76:1803-1811. https:// doi: 10.1111/jan.14365.

30. Thomas J, Harden A. Methods for the thematic synthesis of qualitative research in systematic reviews. BMC Med Res Methodol 2008;8:45. https://doi:10.1186/1471-2288-8-45.

31. Tong A, Flemming K, Mclnnes E, Oliver S, Craig J. Enhancing transparency in reporting the synthesis of qualitative research: ENTREQ. BMC Med Res Methodol 2012; 12: 181. https://doi:10.1186/1471-2288-12-181.

32. McKinney A, Fitzsimons D, Blackwood B, McGaughey J. Patients', relatives' and healthcare professionals' experiences of deterioration and their perceptions of the barriers and facilitators to patient and family-initiated escalation of care in acute adult general hospital wards: a qualitative systematic review protocol. PROSPERO 2018 CRD42018106952 http://www.crd.york.ac.uk/PROSPERO/display_record.php?ID= CRD42018106952. [Accessed 15 Nov 2020].

33. OpenGrey. 2019. http://opengrey.eu/ [Accessed 10 Oct 2019].

34. Considine J, Jones D, Bellomo R. Emergency department rapid response systems: the case for a standardized approach to deteriorating patients. Eur $J$ Emerg Med 2013;1:375-81. https://doi: 10.1097/MEJ.0b013e32835d1e14.

35. Rainey H, Ehrich K, Mackintosh N, Sandall J. The role of patients and their relatives in 'speaking up' about their own safety-a qualitative study of acute illness. Health Expect 2015;18:392-405. https://doi: 10.1111/hex.12044.

36. Guinane J, Hutchinson AM, Bucknall TK. Patient perceptions of deterioration and patient and family activated escalation systems-A qualitative study. J Clin Nurs 2018;27:1621-31. https://doi: 10.1111/jocn.14202.

37. Strickland W, Pirret A, Takerei S. Patient and/or family activated rapid response service: Patients' perceptions of deterioration and need for a service. Intensive Crit Care Nurs 2019;51:20-6. https://doi.org/10.1016/j.iccn.2018.11.007.

38. King L, Peacock G, Crotty M, Clark R. Consumers' perspectives on their involvement in recognizing and responding to patient deteriorationDeveloping a model for consumer reporting. Health Expect 2019;22:385-95. https://doi: 10.1111/hex.12858. 
39. Dwyer TA, Flenady T, Kahl J, Quinney L. Evaluation of a patient and family activated escalation system: Ryan's Rule. Aust Crit Care 2020;33:39-46. https://doi.org/10.1016/j.aucc.2019.01.002.

40. Critical Appraisal Skills Programme (CASP). CASP Checklists. 2018. https://casp-uk.net/casp-tools-checklists/ Oxford. CASP [Accessed 10 July 2018].

41. Popay J, Rogers A, Williams G. Rationale and standards for the systematic review of qualitative literature in health services research. Qual Health Res 1998;8:341-51.

42. Jordan J, Rose L, Dainty KN, Noyes J, Blackwood B. Factors that impact on the use of mechanical ventilation weaning protocols in critically ill adults and children: a qualitative evidence-synthesis. Cochrane Database of Syst Rev, 2016; 1-82. CD011812. https://doi: 10.1002/14651858.CD011812.pub2. [Accessed 20 Oct 2018].

43. Effective Practice and Organisation of Care (EPOC). Data collection form. EPOC Resources for review authors. 2013. Oslo: Norwegian Knowledge Centre for the Health Services.

44. Hoffmann TC, Glasziou PP, Boutron I, et al. Better reporting of interventions: template for intervention description and replication (TIDieR) checklist and guide. BMJ 2014;348:g1687. https://doi: 10.1136/bmj.g1687.

45. Hoffmann TC, Oxman AD, loannidis JP, et al. Enhancing the usability of systematic reviews by improving the consideration and description of interventions. BMJ 2017;358:j2998. http://dx.doi.org/10.1136/bmj.j2998.

46. Higgins JPT, Thomas J, Chandler J, et al. Cochrane Handbook for Systematic $\begin{array}{llll}\text { Reviews of Interventions, } & \text { Version } & 6.0 . & 2019\end{array}$ http://www.training.cochrane.org/handbook. [accessed 1 May 2020].

47. Pedley R, McWilliams C, Lovell K, et al. Qualitative systematic review of barriers and facilitators to patient-involved antipsychotic prescribing. BJPsych Open 2018;4:5-14. https://doi.org/10.1192/bjo.2017.5.

48. Lewin S, Booth A, Glenton C, et al. Applying GRADE-CERQual to qualitative evidence synthesis findings: introduction to the series. Implement Sci 2018; 13:2. https://doi.org/10.1186/s13012-017-0688-3.

49. Buetow SA, Mintoft B. When should patient intuition be taken seriously? J Gen Intern Med 2011;26:433-6. https://doi: 10.1007/s11606-010-1576-6. 
50.World Health Organization (WHO). Patient empowerment and healthcare. WHO guidelines on hand hygiene in health care: first global patient safety challenge clean care is safer care. 2009. https://www.ncbi.nlm.nih.gov/books/NBK144022/ [Accessed 10 October 2019].

51. Berger Z, Flickinger TE, Pfoh E, Martinez KA, Dy SM. Promoting engagement by patients and families to reduce adverse events in acute care settings: a systematic review. BMJ Qual Saf 2014;23:548-55. https://doi:10.1136/bmjqs2012-001769.

52. Mackintosh NJ, Davis RE, Easter A, et al. Interventions to increase patient and family involvement in escalation of care for acute life-threatening illness in community health and hospital settings. Cochrane Database of Syst Rev 2017;10 doi: 10.1002/14651858.CD012829.

53. Holmström I, Röing M. The relation between patient-centeredness and patient empowerment: a discussion on concepts. Patient Educ Couns 2010;79:16772. https://doi:10.1016/j.pec.2009.08.008.

54. Douw G, Schoonhoven L, Holwerda T, et al. Nurses' worry or concern and early recognition of deteriorating patients on general wards in acute care hospitals: a systematic review. Crit Care 2015;19:230. https://doi: 10.1186/s13054-0150950-5.

55. Odell M, Victor C, Oliver D. Nurses' role in detecting deterioration in ward patients: systematic literature review. J Adv Nurs 2009;65:1992-2006. https://doi: 10.1111/j.1365-2648.2009.05109.x.

56. Melin-Johansson C, Palmqvist R, Rönnberg L. Clinical intuition in the nursing process and decision-making-A mixed-studies review. J Clin Nurs 2017;26:3936-49. https://doi: 10.1111/jocn.13814.

57. Vaismoradi M, Jordan S, Kangasniemi M. Patient participation in patient safety and nursing input-a systematic review. J Clin Nurs 2015;24:627-39. https://doi: 10.1111/jocn.12664.

58. Agner J, Braun KL. Patient empowerment: A critique of individualism and systematic review of patient perspectives. Patient Educ Couns 2018;101:205464. https://doi.org/10.1016/j.pec.2018.07.026. 
59. Hrisos S, Thomson R. Seeing it from both sides: do approaches to involving patients in improving their safety risk damaging the trust between patients and healthcare professionals? An interview study. Plos One 2013;8:e80759. https://doi:10.1371/journal.pone.0080759:e80759.

60. Mazor KM, Smith KM, Fisher KA, Gallagher TH. Speak up! Addressing the paradox plaguing patient-centered care. Ann Intern Med 2016;164:618-9. https://doi: 10.7326/M15-2416.

61. Francis R. Report of the Mid Staffordshire NHS Foundation Trust public inquiry: executive summary. The Stationery Office; 2013. https://www.gov.uk/government/publications/report-of-the-mid-staffordshirenhs-foundation-trust-public-inquiry [accessed 18 Oct 2019].

62. Doherty C, Stavropoulou C. Patients' willingness and ability to participate actively in the reduction of clinical errors: a systematic literature review. Social Sci Med 2012;75:257-63. https://doi: 10.1016/j.socscimed.2012.02.056.

63. Tobiano G, Marshall A, Bucknall T, Chaboyer W. Activities patients and nurses undertake to promote patient participation. J Nurs Scholarsh 2016;48:362-70. https://doi: 10.1111/jnu.12219.

64. Ringdal M, Chaboyer W, Ulin K, Bucknall T, Oxelmark L. Patient preferences for participation in patient care and safety activities in hospitals. BMC Nurs 2017;16:69. https://doi. 10.1186/s12912-017-0266-7.

65. Entwistle VA, McCaughan D, Watt IS, et al. Speaking up about safety concerns: multi-setting qualitative study of patients' views and experiences. Qual Saf Health Care 2010;19:e33-. https://doi:10.1136/qshc.2009.039743.

66. Mishra SR, Haldar S, Khelifi M, Pollack AH, Wanda P. Must We Bust the Trust?: Understanding How the Clinician-Patient Relationship Influences Patient Engagement in Safety. In AMIA Annual Symposium Proceedings. 2018, 1425-1434. Retrieved from https://www.ncbi.nlm.nih.gov/pmc/articles/PMC6371248/ [Accessed: 10 October 2019].

67. Frosch DL, May SG, Rendle KA, Tietbohl C, Elwyn G. Authoritarian physicians and patients' fear of being labeled 'difficult' among key obstacles to shared decision making. Health Affairs 2012;31:1030-8. https://doi.org/10.1377/hlthaff.2011.0576. 
68. Schwappach DL, Frank O, Koppenberg J, Müller B, Wasserfallen JB. Patients' and healthcare workers' perceptions of a patient safety advisory. Int J Qual Health Care 2011;23:713-20. https://doi.org/10.1093/intqhc/mzr062.

69. Wolf A, Moore L, Lydahl D, et al. The realities of partnership in person-centred care: a qualitative interview study with patients and professionals. BMJ Open 2017;7:e016491. http://dx.doi.org/10.1136/bmjopen-2017-016491.

70. Bolster D, Manias E. Person-centred interactions between nurses and patients during medication activities in an acute hospital setting: Qualitative observation and interview study. Int $J$ Nurs Stud 2010;47:154-65. https://doi:10.1016/j.ijnurstu.2009.05.021.

71. Bell SK, Martinez W. Every patient should be enabled to stop the line. BMJ Qual Sa. 2019;28:172-6. doi:10.1136/ bmjqs-2018-008714.

72. Protheroe J, Brooks H, Chew-Graham C, Gardner C, Rogers A. 'Permission to participate?' A qualitative study of participation in patients from differing socioeconomic backgrounds. J Health Psychol 2013;18:1046-55. https://doi: $10.1177 / 1359105312459876$. 
To investigate the experiences and

13 patients and 7

Many patients unable to detect deterioration

$\begin{array}{ll}\text { et al. }{ }^{35} & \text { Data collected as pa } \\ \text { larger ethnographic }\end{array}$

UK study

views of patients and relatives whose condition had deteriorated whilst in hospital and to identify the barriers to relatives were interviewed and speak up. Relatives more likely to but depended on previous experience and if encouraged. Uncertainty of significance of symptoms and organizational/cultural barriers and facilitators of patients and relatives speaking up about their worsening condition.

2 Guinane Qualitative exploratory To explore the experiences of et al. ${ }^{36}$ descriptive design

patients who had a period of clinical deterioration and to elicit patient

Australia attitudes towards their potential role in from public setting activating a PFAES.

3 Strickland Qualitative crosset al. ${ }^{37}$ sectional research perspectives of; recognising their acute illness and deterioration, the need for a PFAES and barriers that may prevent them from activating the New design and a co-desig

Zealand service

4 King et Interpretive, qualitative research design

Australia

5 Dwyer et Retrospective RR al. ${ }^{39}$ quantitative (demographic) \&

Australia qualitative (follow-up interviews) data chart review

To explore consumers' experiences of previous reporting of patient deterioration; their preferred educational strategies on this role and recommended pathways in a consumer reporting of patient deterioration model.

To develop an understanding of the Ryan's Rule escalation process. In particular to describe the incidence and circumstances surrounding escalation, clinician and consumer experience of activations and the outcome of activations.
33 patients were interviewed, 17 from

private setting, 16

41 participants

recruited.14 by

PART

(12 patients, 2

relatives),

14 MET (8 patients and 6 relatives)

13 ward (13

patients, 0 relatives) 26 recruited. 9

impact on ability to raise concerns.

Patients largely able to detect deterioration and raise concerns however others were unaware of ways to escalate concerns or felt it was not their role. Personality and previous level of knowledge also acted as barriers or facilitators to escalation.

Patients and relatives are aware of

deterioration and are concerned when

deterioration not recognised/responded to in a timely manner. Some expressed concern regarding escalating care outside own team.

Cultural, personal beliefs and impact on

relationships act as barriers. Others

expressed support for the idea of introducing a patient/family- initiated service.

efforts to report. Previous medical knowledge and confidence act as facilitators to escalation. Lack of resources, feelings of being a burden and perception that clinician knows best act as barriers.

Retrospective chart review of all RR activations for a 2 year period $(\mathrm{N}=57)$

'Not being heard' identified as main reason for patients/relatives activating patient/family escalation. Healthcare staff also identified communication challenges between staff. Discordance exists between healthcare staff and consumers regarding what constitutes a legitimate concern about deterioration. Family initiated rapid response is valued by consumers. patients, 17 relatives deterioration and expressed frustration in
High

Moderate
MET: Medical Emergency Team

PFAES: Patient and Family activated escalation of care scheme
PART: Patient at Risk Team

RR: Ryan's Rule
High 
Table 2: Quality Appraisal of Selected Studies

\begin{tabular}{|c|c|c|c|c|c|c|c|c|c|c|c|}
\hline Source & 1 & 2 & 3 & 4 & 5 & 6 & 7 & 8 & 9 & 10 & $\begin{array}{l}\text { Overall } \\
\text { Quality } \\
\text { Appraisal }\end{array}$ \\
\hline $\begin{array}{l}\text { Rainey et } \\
\text { al. }{ }^{35}\end{array}$ & Yes & Yes & $\begin{array}{l}\text { Yes } \\
\text { (Full) }\end{array}$ & Yes & $\begin{array}{l}\text { Yes } \\
\text { (Full) }\end{array}$ & Yes & Yes & Yes & $\begin{array}{l}\text { Not } \\
\text { Reported }\end{array}$ & Yes & High \\
\hline $\begin{array}{l}\text { Guinane } \\
\text { et al. }{ }^{36}\end{array}$ & Yes & Yes & $\begin{array}{l}\text { Yes } \\
\text { (Full) }\end{array}$ & Yes & $\begin{array}{l}\text { Yes } \\
\text { (Full) }\end{array}$ & Yes & Yes & Yes & $\begin{array}{l}\text { Not } \\
\text { Reported }\end{array}$ & Yes & High \\
\hline $\begin{array}{l}\text { Strickland } \\
\text { et al. }{ }^{37}\end{array}$ & Yes & Yes & $\begin{array}{l}\text { Yes } \\
\text { (Min) }\end{array}$ & No & $\begin{array}{l}\text { Yes } \\
\text { (Full) }\end{array}$ & Yes & Yes & Yes & Yes & Yes & High \\
\hline $\begin{array}{l}\text { King et } \\
\text { al. }\end{array}$ & Yes & Yes & $\begin{array}{l}\text { Yes } \\
\text { (Full) }\end{array}$ & Yes & $\begin{array}{l}\text { Yes } \\
\text { (Full) }\end{array}$ & Yes & Yes & Yes & $\begin{array}{l}\text { Not } \\
\text { Reported }\end{array}$ & Yes & High \\
\hline $\begin{array}{l}\text { Dwyer et } \\
\text { al. } 39\end{array}$ & Yes & $\begin{array}{l}\text { Not } \\
\text { Reported }\end{array}$ & $\begin{array}{l}\text { Yes } \\
\text { (Full) }\end{array}$ & $\begin{array}{l}\text { Not } \\
\text { Reported }\end{array}$ & $\begin{array}{l}\text { Yes } \\
\text { (Full) }\end{array}$ & Yes & $\begin{array}{l}\text { Not } \\
\text { Reported }\end{array}$ & Yes & $\begin{array}{l}\text { Not } \\
\text { Reported }\end{array}$ & Yes & Moderate \\
\hline
\end{tabular}

1-Is there a logical fit between stated research aim(s) and method(s) used? 2-Is the recruitment strategy appropriate to the aims of the research? 3-Is there detailed evidence of steps taken in data collection? 4-Were the data audio-recorded and transcribed? 5-Is there detailed statement of steps taken in data analysis? 6-Did data analysis involve inter-rater discussion? 7-Was there consideration of disconfirming findings? 8-Is there a clear and detailed statement of findings? 9-Is there evidence of a reflexive concern with the conduct of the study? 10-Is there evidence of analysis and interpretation of the findings at a conceptual and theoretical level?

(Adapted from Jordan et al. ${ }^{42}$ ) 
Table 3: CERQual Summary of Qualitative Findings

Objective: To identify, appraise and synthesise qualitative research evidence to determine adult patients' and relatives' experiences of acute deterioration in hospital

\section{Perspective: Patient/ relative perceptions of knowing that their health had deteriorated while in hospital}

Analytical Theme 1: Inherent Capabilities

Review Finding

CERQual

Explanation of CERQual Assessment

Studies

Assessment of

Contributing to

Confidence

Knowing self/ significant other: patient and Moderate
relative awareness of a change in condition confidence

This finding was graded as moderate confidence because of minor concerns about methodological

Review Finding

limitations (4 studies had minor methodological limitations) and adequacy (limited studies,

however overall provided moderately rich data) and moderate concerns about relevance (studies

mainly applicable to Australia).

Appreciation of significance:

Moderate

patient/relative understanding of extent of confidence

or severity of deterioration in health or

This finding was graded as moderate confidence because of minor concerns about methodological

35-39

condition

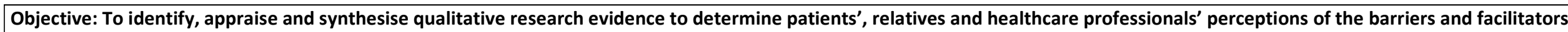
to patient and family-initiated escalation of care in acute adult hospital wards

Analytical Theme 2: Empowering Influencers

Personal characteristics: individual or Moderate

personal factors that influence involvement confidence

in care

Perceptions of role:

Moderate

healthcare professional/ patient/relative confidence

perceptions of role in patient deterioration/

escalation of care

Communication skills: patient/relative

Moderate

perceptions of being heard vs not being confidence

heard

Developed relationships: patient/relative

and healthcare professionals' perceptions

and understanding of extent of rapport

Organisational / Logistical factors:

Moderate

confidence

contextual factors, human and financial

Moderate resources

This finding was graded as moderate confidence because of minor concerns about methodological 35-39

limitations and adequacy and moderate concerns about relevance (studies addressed only a sub-

set of the review domains).

This finding was graded as moderate confidence because of minor concerns about methodological 35-39

limitations, coherence (data was mainly consistent and provided explanations for any contrasting

findings) and adequacy and moderate concerns about relevance.

This finding was graded as moderate confidence because of minor concerns about methodological 35-39 limitations, coherence and adequacy and moderate concerns about relevance.

This finding was graded as moderate confidence because of minor concerns about methodological 35-39 limitations, coherence and adequacy and moderate concerns about relevance.

This finding was graded as moderate confidence because of minor concerns about methodological 35-38 limitations, coherence and adequacy and moderate concerns about relevance. 


\section{Appendix 1: Database search}

Database(s): Ovid MEDLINE(R) ALL 1946 to August 2019

Search Strategy:

\section{Searches}

1 "deterioration".mp. or CLINICAL DETERIORATION/

2 "clinical deterioration".mp. or Clinical Deterioration/

3 "deteriorating patient*".mp.

4 Hospital Rapid Response Team/ or "family-initiated rapid response".mp.

5 Hospital Rapid Response Team/ or "family-initiated rapid response system*".mp.

6 "family-initiated escalation of care".mp. or Hospital Rapid Response Team/ "family-activated escalation of care".mp. [mp=title, abstract, original title, name of substance word, subject heading word, floating sub-heading word, keyword heading word, protocol

7 supplementary concept word, rare disease supplementary concept word, unique identifier, synonyms]

8 "calling for help".mp.

9 "condition help".mp.

10 "medical emergency team*".mp.

11 "rapid response system".mp.

121 or 2 or 3 or 4 or 5 or 6 or 7 or 8 or 9 or 10 or 11

13 Family/ or "famil*".mp.

14 "relativ*".mp.

15 "patients".mp. or PATIENTS/

16 Health Personnel/ or Nursing Staff, Hospital/ or "healthcare staff".mp.

17 "nurse*".mp.

18 "doctor*".mp. or Physicians/

19 "medical staff".mp. or Medical Staff, Hospital/ or Medical Staff/

20 "critical care outreach team".mp.

2113 or 14 or 15 or 16 or 17 or 18 or 19 or 20

22 "hospital".mp. or Hospitals/

23 "general ward"*.mp.

2422 or 23

25 "experience".mp.

26 "views".mp. 


\begin{tabular}{|l|l|}
\hline 27 & "opinions".mp. or Attitude/ \\
\hline 28 & "perceptions".mp. or Perception/ \\
\hline 29 & ATTITUDE/ or "attitude".mp. \\
\hline 30 & 25 or 26 or 27 or 28 or 29 \\
\hline 31 & 12 and 21 and 24 and 30 \\
\hline 32 & limit 31 to $y r=" 2005$-Current" \\
\hline
\end{tabular}

Database(s): Embase 1974 to 2019

Search Strategy:

\# Searches

1 deterioration.mp. or deterioration/

2 clinical deterioration.mp.

3 deteriorating patient ${ }^{*} . \mathrm{mp}$.

4 rapid response team/ or family-initiated rapid response.mp.

5 family-initiated rapid response system*.mp.

6 family-initiated escalation of care.mp.

7 calling for help.mp.

family-activated escalation of care.mp. [mp=title, abstract, heading word, drug trade name, original title,

8 device manufacturer, drug manufacturer, device trade name, keyword, floating subheading word, candidate term word]

9 condition help.mp.

10 medical emergency team*.mp.

11 rapid response system.mp. or rapid response team/

12 or 2 or 3 or 4 or 5 or 6 or 7 or 8 or 9 or 10 or 11

13 family/ or famil ${ }^{*} . \mathrm{mp}$.

14 relative/ or relativ*.mp.

15 patients.mp. or patient/

16 medical staff/ or health care personnel/ or nursing staff/ or healthcare staff.mp.

17 staff nurse/ or nurse*.mp. or nurse/

18 doctor*.mp.

19 medical staff.mp. or medical staff/

20 critical care outreach team.mp.

2113 or 14 or 15 or 16 or 17 or 18 or 19 or 20 


\begin{tabular}{|l|l|}
\hline 22 & hospital/ or hospital.mp. \\
\hline 23 & ward/ or general ward*.mp. \\
\hline 24 & 22 or 23 \\
\hline 25 & experience/ or experience.mp. \\
\hline 26 & views.mp. \\
\hline 27 & opinions.mp. \\
\hline 28 & perception/ or perceptions.mp. \\
\hline 29 & attitude.mp. or attitude/ \\
\hline 30 & 25 or 26 or 27 or 28 or 29 \\
\hline 31 & 12 and 21 and 24 and 30 \\
\hline 32 & limit 31 to yr="2005 -Current" \\
\hline
\end{tabular}

Database(s): PsycINFO 1967 to 2019

Search Strategy:

\section{\# Searches}

1 deterioration.mp.

2 clinical deterioration.mp.

3 deteriorating patient ${ }^{*} . \mathrm{mp}$.

4 family-initiated rapid response.mp.

5 family-initiated rapid response system*.mp.

6 family-initiated escalation of care.mp.

family-activated escalation of care. $\mathrm{mp}$. [mp=title, abstract, heading word, table of contents, key concepts,

original title, tests \& measures]

8 calling for help.mp.

9 condition help.mp.

10 medical emergency team*.mp.

11 rapid response system.mp.

121 or 2 or 3 or 4 or 5 or 6 or 7 or 8 or 9 or 10 or 11

13 exp Family/ or famil ${ }^{*}$.mp.

14 relativ*.mp $^{*}$

15 exp PATIENTS/ or patients.mp.

16 exp Health Personnel/ or healthcare staff.mp.

17 nurse*.mp. or exp NURSES/

18 exp Physicians/ or doctor*.mp.

19 exp Physicians/ or medical staff.mp. 


\begin{tabular}{|l|l|}
\hline 20 & critical care outreach team.mp. \\
\hline 21 & 13 or 14 or 15 or 16 or 17 or 18 or 19 or 20 \\
\hline 22 & exp HOSPITALS/ or hospital.mp. \\
\hline 23 & general ward*.mp. \\
\hline 24 & 22 or 23 \\
\hline 25 & experience.mp. \\
\hline 26 & views.mp. \\
\hline 27 & opinions.mp. or exp Attitudes/ \\
\hline 28 & perceptions.mp. or exp PERCEPTION/ \\
\hline 29 & attitude.mp. or exp ATTITUDES/ \\
\hline 30 & 25 or 26 or 27 or 28 or 29 \\
\hline 31 & 12 and 21 and 24 and 30 \\
\hline 32 & limit 31 to yr="2005 -Current" \\
\hline
\end{tabular}

\section{CINAHL (To 2019)}

\begin{tabular}{|l|l|}
\hline S12 AND S21 AND S24 & $\begin{array}{l}\text { Limiters - Publication Year: 2005-2019 } \\
\text { AND S30 }\end{array}$ \\
\hline S31 & S12 AND S21 AND S24 AND S30 \\
\hline S30 & S25 OR S26 OR S27 OR S28 OR S29 \\
\hline S29 & (MH "Attitude") OR "attitude" \\
\hline S28 & "perceptions" \\
\hline S27 & "opinions" \\
\hline S26 & "views" \\
\hline S25 & "experience" \\
\hline S24 & S22 OR S23 \\
\hline S23 & "general ward*" \\
\hline S22 & "hospital" \\
\hline S21 & S13 OR S14 OR S15 OR S16 OR S17 OR S18 OR S19 OR S20 \\
\hline S20 & "critical care outreach team" \\
\hline S19 & $\begin{array}{l}\text { (MH "Medical Staff") OR "medical staff" OR (MH "Medical Staff, } \\
\text { Hospital") }\end{array}$ \\
\hline S18 & (MH "Physicians") OR "doctor*" \\
\hline S17 & "nurse*" \\
\hline S16 & $\begin{array}{l}\text { (MH "Health Personnel") OR "healthcare staff" OR (MH "Staff } \\
\text { Nurses") OR (MH "Nursing Staff, Hospital") OR (MH "Medical } \\
\text { Staff, Hospital") }\end{array}$ \\
\hline S15 & (MH "Patients") OR "patients" \\
\hline S14 & (MH "Extended Family") OR "relativ*" \\
\hline S13 & (MH "Family") OR "famil*" \\
\hline S12 & $\begin{array}{l}\text { S1 OR S2 OR S3 OR S4 OR S5 OR S6 OR S7 OR S8 OR S9 OR S10 OR } \\
\text { S11 }\end{array}$ \\
\hline S11 & "rapid response system" \\
\hline S10 & "medical emergency team*" \\
\hline
\end{tabular}




\begin{tabular}{|l|l|}
\hline S9 & "condition help" \\
\hline S8 & "calling for help" \\
\hline S7 & "family-activated escalation of care" \\
\hline S6 & "family-initiated escalation of care" \\
\hline S5 & $\begin{array}{l}\text { "family-initiated rapid response system*" OR (MH "Rapid } \\
\text { Response Team") }\end{array}$ \\
\hline S4 & "family-initiated rapid response" \\
\hline S3 & "deteriorating patient*" \\
\hline S2 & "clinical deterioration" \\
\hline S1 & "deterioration" \\
\hline
\end{tabular}


Appendix 2: PRISMA flow diagram for deterioration and patient and family-initiated escalation of care search.
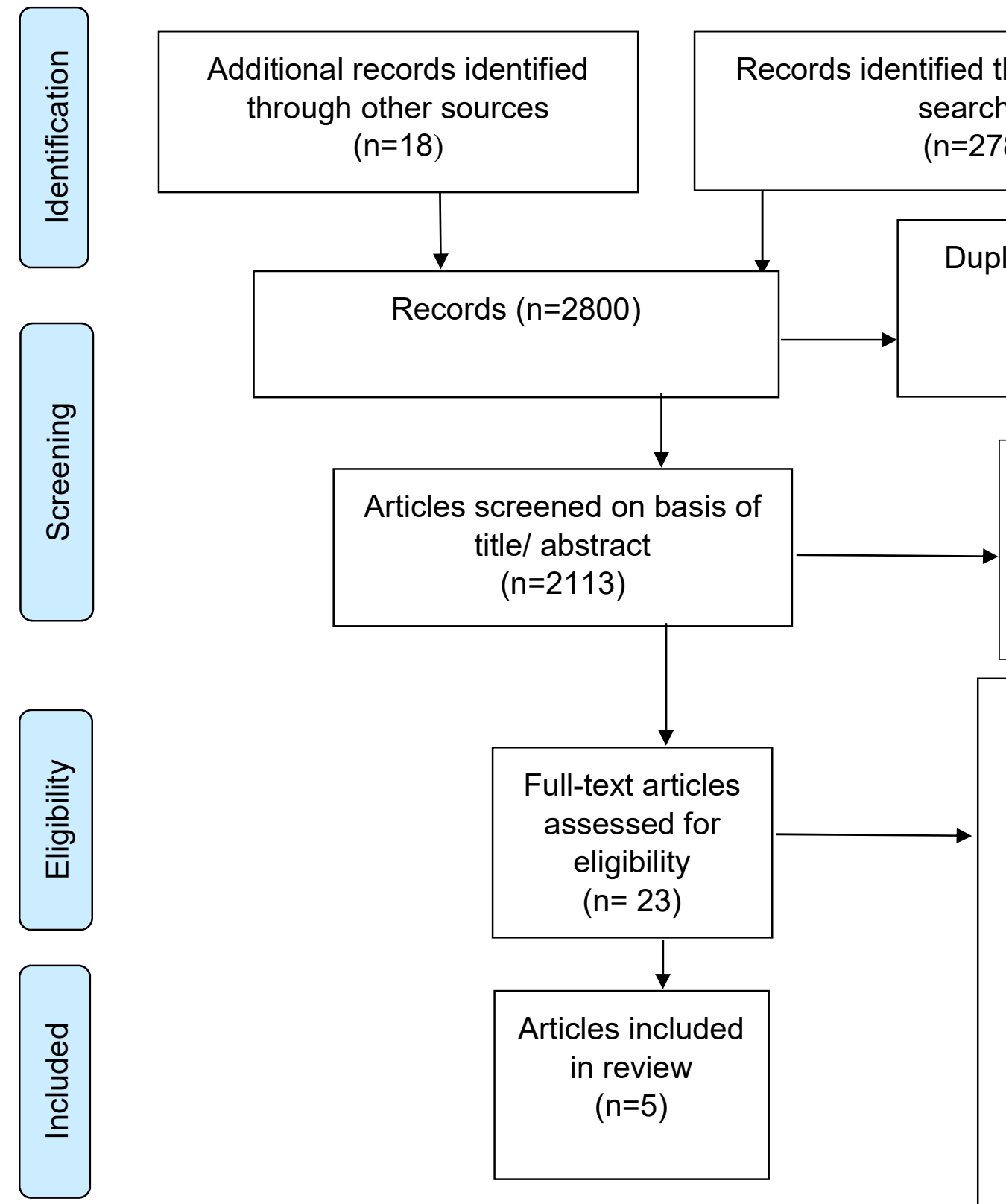

Articles excluded $(n=2090)$ as did not meet inclusion criteria $(n=687)$

Full-text articles excluded, with explanations: $(n=18)$

- Inappropriate Phenomenon of interest $(n=10)$

- Inappropriate context/setting $(\mathrm{n}=2)$

- No qualitative element $(n=6)$ 
Objective: To identify, appraise and synthesise qualitative research evidence to (a) explore patients' and relatives' experiences of deterioration and (b) patients', relatives' and healthcare professionals' perceptions of the barriers or facilitators to patient and family-initiated escalation of care in acute adult hospital wards.

\section{Analytical theme 1: Inherent capabilities}

\begin{tabular}{|c|c|c|c|c|c|c|c|}
\hline $\begin{array}{l}\text { Review } \\
\text { Findings }\end{array}$ & $\begin{array}{l}\text { Studies } \\
\text { contributing } \\
\text { to the } \\
\text { review of } \\
\text { findings }\end{array}$ & $\begin{array}{l}\text { Assessment of } \\
\text { Methodological } \\
\text { Limitations }\end{array}$ & $\begin{array}{l}\text { Assessment of } \\
\text { Relevance }\end{array}$ & $\begin{array}{l}\text { Assessment of } \\
\text { Coherence }\end{array}$ & $\begin{array}{l}\text { Assessment of } \\
\text { Adequacy }\end{array}$ & $\begin{array}{l}\text { Overall } \\
\text { CerQual } \\
\text { Assessment } \\
\text { of } \\
\text { Confidence }\end{array}$ & $\begin{array}{l}\text { Explanation of } \\
\text { Judgement }\end{array}$ \\
\hline $\begin{array}{l}\text { Knowing self/ } \\
\text { significant other }\end{array}$ & $35-38$ & $\begin{array}{l}\text { Minor methodological } \\
\text { limitations. ( } 4 \text { studies with } \\
\text { minor limitations as } \\
\text { minimal detail was } \\
\text { provided on steps taken } \\
\text { in data collection }{ }^{37} \text {, data } \\
\text { was not audio-recorded } \\
\text { and transcribed }{ }^{37} \text {, and } \\
\text { reflective concerns were } \\
\left.\text { not reported }{ }^{35,36,38}\right) \text {. }\end{array}$ & $\begin{array}{l}\text { Moderate concerns } \\
\text { about relevance } \\
\text { (partial relevance as } 3 \\
\text { studies from Australia } \\
\text { and New Zealand and } \\
\text { only one from UK. All } \\
4 \text { studies only } \\
\text { addressed a subset of } \\
\text { the relevant review } \\
\text { domains). }\end{array}$ & $\begin{array}{l}\text { No concerns } \\
\text { about } \\
\text { coherence } \\
\text { (data consistent } \\
\text { within and } \\
\text { across all } \\
\text { studies). }\end{array}$ & $\begin{array}{l}\text { Minor concerns } \\
\text { about } \\
\text { adequacy (4 } \\
\text { studies offering } \\
\text { moderately rich } \\
\text { data overall). }\end{array}$ & $\begin{array}{l}\text { Moderate } \\
\text { confidence }\end{array}$ & $\begin{array}{l}\text { This finding was } \\
\text { graded as moderate } \\
\text { confidence because } \\
\text { of minor concerns } \\
\text { about methodological } \\
\text { limitations and } \\
\text { adequacy and } \\
\text { moderate concerns } \\
\text { about relevance. }\end{array}$ \\
\hline $\begin{array}{l}\text { Appreciation of } \\
\text { significance of } \\
\text { symptoms }\end{array}$ & $35-39$ & $\begin{array}{l}\text { Minor methodological } \\
\text { limitations. ( } 4 \text { studies }{ }^{35-38} \\
\text { with minor limitations as } \\
\text { outlined above. } 1 \text { study }{ }^{39} \\
\text { with moderate limitations } \\
\text { as recruitment strategy } \\
\text { was not clearly reported, } \\
\text { data was not audio- } \\
\text { recorded and transcribed, } \\
\text { disconfirming of findings }\end{array}$ & $\begin{array}{l}\text { Moderate concerns } \\
\text { about relevance } \\
\text { (partial relevance as } 4 \\
\text { studies from Australia } \\
\text { and New Zealand and } \\
\text { only } 1 \text { from UK. All } 5 \\
\text { studies only } \\
\text { addressed a subset of } \\
\text { the relevant review } \\
\text { domains). }\end{array}$ & $\begin{array}{l}\text { No concerns } \\
\text { about } \\
\text { coherence } \\
\text { (data consistent } \\
\text { within and } \\
\text { across all } \\
\text { studies). }\end{array}$ & $\begin{array}{l}\text { Minor concerns } \\
\text { about } \\
\text { adequacy ( } 5 \\
\text { studies offering } \\
\text { moderately rich } \\
\text { data overall). }\end{array}$ & $\begin{array}{l}\text { Moderate } \\
\text { confidence }\end{array}$ & $\begin{array}{l}\text { This finding was } \\
\text { graded as moderate } \\
\text { confidence because } \\
\text { of minor concerns } \\
\text { about methodological } \\
\text { limitations and } \\
\text { adequacy and } \\
\text { moderate concerns } \\
\text { about relevance. }\end{array}$ \\
\hline
\end{tabular}

was not reported and

reflective concerns were

not reported). 
Analytical theme 2: Empowerment influencers

\begin{tabular}{|c|c|c|c|c|c|c|c|}
\hline $\begin{array}{l}\text { Personal } \\
\text { characteristics } \\
\text { influence } \\
\text { involvement }\end{array}$ & $35-39$ & $\begin{array}{l}\text { Minor methodological } \\
\text { limitations. ( } 4 \text { studies with } \\
\text { minor and } 1 \text { study with } \\
\text { moderate methodological } \\
\text { limitations). }\end{array}$ & $\begin{array}{l}\text { Moderate concerns } \\
\text { about relevance } \\
\text { (partial relevance as } 4 \\
\text { studies from Australia } \\
\text { and New Zealand and } \\
\text { only } 1 \text { from UK. All } 5 \\
\text { studies only } \\
\text { addressed a subset of } \\
\text { the relevant review } \\
\text { domains). }\end{array}$ & $\begin{array}{l}\text { No concerns } \\
\text { about } \\
\text { coherence } \\
\text { (data consistent } \\
\text { within and } \\
\text { across all } \\
\text { studies). }\end{array}$ & $\begin{array}{l}\text { Minor concerns } \\
\text { about } \\
\text { adequacy ( } 5 \\
\text { studies offering } \\
\text { moderately rich } \\
\text { data overall). }\end{array}$ & $\begin{array}{l}\text { Moderate } \\
\text { confidence }\end{array}$ & $\begin{array}{l}\text { This finding was } \\
\text { graded as moderate } \\
\text { confidence because } \\
\text { of minor concerns } \\
\text { about methodological } \\
\text { limitations and } \\
\text { adequacy and } \\
\text { moderate concerns } \\
\text { about relevance. }\end{array}$ \\
\hline $\begin{array}{l}\text { Perceptions of } \\
\text { role }\end{array}$ & 35-39 & $\begin{array}{l}\text { Minor methodological } \\
\text { limitations. ( } 4 \text { studies with } \\
\text { minor and } 1 \text { study with } \\
\text { moderate methodological } \\
\text { limitations). }\end{array}$ & $\begin{array}{l}\text { Moderate concerns } \\
\text { about relevance } \\
\text { (partial relevance as } 4 \\
\text { studies from Australia } \\
\text { and New Zealand and } \\
\text { only } 1 \text { from UK. All } 5 \\
\text { studies only } \\
\text { addressed a subset of } \\
\text { the relevant review } \\
\text { domains). }\end{array}$ & $\begin{array}{l}\text { Minor concerns } \\
\text { about } \\
\text { coherence } \\
\text { (data } \\
\text { reasonably } \\
\text { consistent } \\
\text { within and } \\
\text { across all } \\
\text { studies. One } \\
\text { study provided } \\
\text { thin data). }\end{array}$ & $\begin{array}{l}\text { Minor concerns } \\
\text { about } \\
\text { adequacy ( } 5 \\
\text { studies offering } \\
\text { moderately rich } \\
\text { data overall). }\end{array}$ & $\begin{array}{l}\text { Moderate } \\
\text { confidence }\end{array}$ & $\begin{array}{l}\text { This finding was } \\
\text { graded as moderate } \\
\text { confidence because } \\
\text { of minor concerns } \\
\text { about methodological } \\
\text { limitations, } \\
\text { coherence and } \\
\text { adequacy and } \\
\text { moderate concerns } \\
\text { about relevance. }\end{array}$ \\
\hline $\begin{array}{l}\text { Communication } \\
\text { skills - being } \\
\text { heard vs not } \\
\text { being heard }\end{array}$ & 35-39 & $\begin{array}{l}\text { Minor methodological } \\
\text { limitations. ( } 4 \text { studies with } \\
\text { minor and } 1 \text { study with } \\
\text { moderate methodological } \\
\text { limitations). }\end{array}$ & $\begin{array}{l}\text { Moderate concerns } \\
\text { about relevance } \\
\text { (partial relevance as } 4 \\
\text { studies from Australia } \\
\text { and New Zealand and } \\
\text { only } 1 \text { from UK. All } 5 \\
\text { studies only } \\
\text { addressed a subset of } \\
\text { the relevant review } \\
\text { domains). }\end{array}$ & $\begin{array}{l}\text { Minor concerns } \\
\text { about } \\
\text { coherence } \\
\text { (data } \\
\text { reasonably } \\
\text { consistent } \\
\text { within and } \\
\text { across all } \\
\text { studies. } \\
\text { Explaining the } \\
\text { variation in data } \\
\text { across } \\
\text { individual } \\
\text { studies } \\
\text { contributing to } \\
\text { this finding was } \\
\text { thin). }\end{array}$ & $\begin{array}{l}\text { Minor concerns } \\
\text { about } \\
\text { adequacy ( } 5 \\
\text { studies offering } \\
\text { moderately rich } \\
\text { data overall). }\end{array}$ & $\begin{array}{l}\text { Moderate } \\
\text { confidence }\end{array}$ & $\begin{array}{l}\text { This finding was } \\
\text { graded as moderate } \\
\text { confidence because } \\
\text { of minor concerns } \\
\text { about methodological } \\
\text { limitations, } \\
\text { coherence and } \\
\text { adequacy and } \\
\text { moderate concerns } \\
\text { about relevance. }\end{array}$ \\
\hline
\end{tabular}




\begin{tabular}{|c|c|c|c|c|c|c|c|}
\hline $\begin{array}{l}\text { Developed } \\
\text { relationships }\end{array}$ & 35-39 & $\begin{array}{l}\text { Minor methodological } \\
\text { limitations. ( } 4 \text { studies with } \\
\text { minor and } 1 \text { study with } \\
\text { moderate methodological } \\
\text { limitations). }\end{array}$ & $\begin{array}{l}\text { Moderate concerns } \\
\text { about relevance } \\
\text { (partial relevance as } 4 \\
\text { studies from Australia } \\
\text { and New Zealand and } \\
\text { only } 1 \text { from UK. All } 5 \\
\text { studies only } \\
\text { addressed a subset of } \\
\text { the relevant review } \\
\text { domains). }\end{array}$ & $\begin{array}{l}\text { Minor concerns } \\
\text { about } \\
\text { coherence } \\
\text { (data } \\
\text { reasonably } \\
\text { consistent } \\
\text { within and } \\
\text { across all } \\
\text { studies. } \\
\text { Explaining the } \\
\text { variation in data } \\
\text { across } \\
\text { individual } \\
\text { studies } \\
\text { contributing to } \\
\text { this finding was } \\
\text { thin). }\end{array}$ & $\begin{array}{l}\text { Minor concerns } \\
\text { about } \\
\text { adequacy ( } 5 \\
\text { studies offering } \\
\text { moderately rich } \\
\text { data overall). }\end{array}$ & $\begin{array}{l}\text { Moderate } \\
\text { confidence }\end{array}$ & $\begin{array}{l}\text { This finding was } \\
\text { graded as moderate } \\
\text { confidence because } \\
\text { of minor concerns } \\
\text { about methodological } \\
\text { limitations, } \\
\text { coherence and } \\
\text { adequacy and } \\
\text { moderate concerns } \\
\text { about relevance. }\end{array}$ \\
\hline $\begin{array}{l}\text { Organisational / } \\
\text { Logistical } \\
\text { factors }\end{array}$ & $35-38$ & $\begin{array}{l}\text { Minor methodological } \\
\text { limitations. (4 studies with } \\
\text { minor methodological } \\
\text { limitations). }\end{array}$ & $\begin{array}{l}\text { Moderate concerns } \\
\text { about relevance } \\
\text { (partial relevance as } 3 \\
\text { studies from Australia } \\
\text { and New Zealand and } \\
\text { only one from UK. All } \\
4 \text { studies only } \\
\text { addressed a subset of } \\
\text { the relevant review } \\
\text { domains). }\end{array}$ & $\begin{array}{l}\text { Minor concerns } \\
\text { about } \\
\text { coherence } \\
\text { (data } \\
\text { reasonably } \\
\text { consistent } \\
\text { within and } \\
\text { across all } \\
\text { studies. } \\
\text { Explaining the } \\
\text { variation in data } \\
\text { across } \\
\text { individual } \\
\text { studies } \\
\text { contributing to } \\
\text { this finding was } \\
\text { thin). }\end{array}$ & $\begin{array}{l}\text { Minor concerns } \\
\text { about } \\
\text { adequacy (4 } \\
\text { studies offering } \\
\text { moderately rich } \\
\text { data overall). }\end{array}$ & $\begin{array}{l}\text { Moderate } \\
\text { confidence }\end{array}$ & $\begin{array}{l}\text { This finding was } \\
\text { graded as moderate } \\
\text { confidence because } \\
\text { of minor concerns } \\
\text { about methodological } \\
\text { limitations, } \\
\text { coherence and } \\
\text { adequacy and } \\
\text { moderate concerns } \\
\text { about relevance. }\end{array}$ \\
\hline
\end{tabular}

\section{Descriptions of level of confidence ${ }^{4}$}

High confidence: It is highly likely that the review finding is a reasonable representation of the phenomenon of interest.

Moderate confidence: It is likely that the review finding is a reasonable representation of the phenomenon of interest.

Low confidence: It is possible that the review finding is a reasonable representation of the phenomenon of interest.

Very low confidence: It is not clear whether the review finding is a reasonable representation of the phenomenon of interest. 